\title{
Evidence-Based PET for Infectious and Inflammatory Diseases
}

\author{
Giorgio Treglia and Barbara Muoio
}

\subsection{Introduction}

Nuclear medicine techniques are non-invasive tools that can early detect pathophysiological changes in affected tissues in patients with inflammatory or infectious diseases. These changes usually occur before clinical onset of symptoms and before the development of anatomical changes detected by radiological techniques [1, 2]. Currently, hybrid imaging techniques as positron emission tomography/ computed tomography (PET/CT) may provide functional and morphological information for early diagnosis of infectious and inflammatory diseases [1,2].

The ability of Fluorine-18 fluorodeoxyglucose $\left({ }^{18} \mathrm{~F}-\mathrm{FDG}\right) \mathrm{PET} / \mathrm{CT}$ to identify sites of inflamma-

\footnotetext{
G. Treglia $(\bowtie)$

Clinic of Nuclear Medicine and PET/CT Center, Imaging Institute of Southern Switzerland, Ente Ospedaliero Cantonale,

Bellinzona and Lugano, Switzerland

Health Technology Assessment Unit, Ente Ospedaliero Cantonale, Bellinzona, Switzerland

Department of Nuclear Medicine and Molecular Imaging, Lausanne University Hospital and University of Lausanne, Lausanne, Switzerland e-mail: giorgio.treglia@eoc.ch

B. Muoio

Clinic of Oncology and Internal Medicine,

San Giovanni Hospital, Oncology Institute of Southern Switzerland, Ente Ospedaliero Cantonale, Bellinzona, Switzerland
}

tion and infection is mainly related to the glycolytic activity of the cells involved in the inflammatory response [3, 4]. Enough evidence in the literature already exists about the diagnostic performance of ${ }^{18} \mathrm{~F}-\mathrm{FDG} \mathrm{PET} / \mathrm{CT}$ in the diagnosis and management of several infectious and inflammatory diseases [5]. The results of the selected articles, including pooled values and 95\% confidence interval $(95 \% \mathrm{CI})$, are presented in Table 12.1 and summarized here below.

\subsection{Fever of Unknown Origin (FUO)}

Fever of unknown origin (FUO) is commonly defined as temperature $\geq 38.3{ }^{\circ} \mathrm{C}$ on at least two occasions, duration of illness $\geq 3$ weeks or multiple febrile episodes in $\geq 3$ weeks, not immunocompromised patient, and uncertain diagnosis despite thorough history-taking, physical examination, and obligatory investigations [6]. The diagnosis in patients with FUO is a challenging medical problem; the cause of FUO may be infectious diseases, non-infectious inflammatory diseases, or tumors, and ${ }^{18} \mathrm{~F}$-FDG PET/CT detecting foci of increased glucose metabolism may be used for revealing the source of fever [6]. Several meta-analyses have estimated the diagnostic performance of ${ }^{18} \mathrm{~F}-\mathrm{FDG}$ PET/CT in the assessment of FUO unidentified by conventional workup [7-13]. 
Table 12.1 Characteristics and main findings of included meta-analyses on the diagnostic performance of ${ }^{18} \mathrm{~F}-\mathrm{FDG}$ $\mathrm{PET} / \mathrm{CT}$ in infectious or inflammatory diseases

\begin{tabular}{|c|c|c|c|c|c|c|c|}
\hline Topic & Authors & $\begin{array}{l}\text { Patients } \\
\text { included }\end{array}$ & $\begin{array}{l}\text { Sensitivity } \\
(95 \% \mathrm{CI})\end{array}$ & $\begin{array}{l}\text { Specificity } \\
(95 \% \mathrm{CI})\end{array}$ & $\begin{array}{l}\mathrm{LR}+ \\
(95 \% \mathrm{CI})\end{array}$ & $\begin{array}{l}\text { LR- } \\
(95 \% \mathrm{CI})\end{array}$ & $\begin{array}{l}\text { DOR } \\
(95 \% \mathrm{CI})\end{array}$ \\
\hline \multirow[t]{7}{*}{$\begin{array}{l}\text { Fever of } \\
\text { unknown origin }\end{array}$} & Dong et al. [7] & 174 & $\begin{array}{l}98.2 \% \\
(93.6-99.8)\end{array}$ & $\begin{array}{l}85.9 \% \\
(75.0-93.4)\end{array}$ & $\begin{array}{l}5.8 \\
(3.3-10)\end{array}$ & $\begin{array}{l}0.05 \\
(0.01-0.25)\end{array}$ & $\begin{array}{l}7.1 \\
(0.7-67.4)\end{array}$ \\
\hline & Hao et al. [8] & 595 & $\begin{array}{l}85 \% \\
(81-88)\end{array}$ & NR & NR & NR & NR \\
\hline & Besson et al. [9] & 401 & NR & NR & NR & NR & NR \\
\hline & Takeuchi et al. [10] & 1137 & $\begin{array}{l}86 \% \\
(81-90)\end{array}$ & $\begin{array}{l}52 \% \\
(36-67)\end{array}$ & NR & NR & NR \\
\hline & Bharucha et al. [11] & 905 & NR & NR & NR & NR & NR \\
\hline & Kan et al. [12] & 1927 & $\begin{array}{l}84 \% \\
(79-89)\end{array}$ & $\begin{array}{l}63 \% \\
(49-75)\end{array}$ & $\begin{array}{l}2.3 \\
(1.5-3.4)\end{array}$ & $\begin{array}{l}0.25 \\
(0.16-0.38)\end{array}$ & $\begin{array}{l}9 \\
(4-20)\end{array}$ \\
\hline & Takeuchi et al. [13] & 418 & NR & NR & NR & NR & NR \\
\hline \multirow[t]{9}{*}{$\begin{array}{l}\text { Large vessel } \\
\text { vasculitis }\end{array}$} & Besson et al. ${ }^{\mathrm{a}}[19]$ & 283 & $\begin{array}{l}{[\mathrm{GCA}] 80 \%} \\
(63-91)\end{array}$ & $\begin{array}{l}{[\mathrm{GCA}] 89 \%} \\
(78-94)\end{array}$ & $\begin{array}{l}{[\mathrm{GCA}]} \\
6.73 \\
(3.5-12.8)\end{array}$ & $\begin{array}{l}{[\mathrm{GCA}] 0.25} \\
(0.13-0.46)\end{array}$ & NR \\
\hline & Cheng et al. ${ }^{\mathrm{a}}[20]$ & 142 & $\begin{array}{l}{[\mathrm{TA}] 70.1 \%} \\
(58.6-80)\end{array}$ & $\begin{array}{l}{[\mathrm{TA}] 77.2 \%} \\
(64.2-87.3)\end{array}$ & $\begin{array}{l}{[\mathrm{TA}] 2.3} \\
(1.1-4.8)\end{array}$ & $\begin{array}{l}{[\mathrm{TA}] 0.34} \\
(0.14-0.82)\end{array}$ & $\begin{array}{l}{[\mathrm{TA}] 7.5} \\
(1.6-34)\end{array}$ \\
\hline & Soussan et al. ${ }^{\mathrm{a}}[21]$ & 712 & $\begin{array}{l}{[\mathrm{GCA}] 90 \%} \\
(79-96)\end{array}$ & $\begin{array}{l}\text { [GCA] } 98 \% \\
(94-99)\end{array}$ & $\begin{array}{l}\text { [GCA] } \\
28.7 \\
(11.5-71.6)\end{array}$ & $\begin{array}{l}{[\mathrm{GCA}] 0.15} \\
(0.07-0.29)\end{array}$ & $\begin{array}{l}\text { [GCA] } \\
256.3 \\
(70.8-927)\end{array}$ \\
\hline & & & $\begin{array}{l}{[\mathrm{TA}] 87 \%} \\
(78-93)\end{array}$ & $\begin{array}{l}{[\mathrm{TA}] 73 \%} \\
(63-81)\end{array}$ & $\begin{array}{l}{[\mathrm{TA}] 4.2} \\
(1.5-12)\end{array}$ & $\begin{array}{l}{[\mathrm{TA}] 0.2} \\
(0.1-0.5)\end{array}$ & $\begin{array}{l}{[\mathrm{TA}] 19.8} \\
(4.5-87.6)\end{array}$ \\
\hline & & & $\begin{array}{l}{\left[\mathrm{TA}^{+}\right] 84 \%} \\
(73-92)\end{array}$ & $\begin{array}{l}{\left[\mathrm{TA}^{+}\right] 84 \%} \\
(73-92)\end{array}$ & $\begin{array}{l}{\left[\mathrm{TA}^{+}\right] 4.6} \\
(2.1-9.9)\end{array}$ & $\begin{array}{l}{\left[\mathrm{TA}^{+}\right] 0.2} \\
(0.1-0.5)\end{array}$ & $\begin{array}{l}{\left[\mathrm{TA}^{+}\right] 23.4} \\
(5.2- \\
105.2)\end{array}$ \\
\hline & Lee et al. [22] & 95 & $\begin{array}{l}83.9 \% \\
(71.7-92.4)\end{array}$ & $\begin{array}{l}87.2 \% \\
(72.6-95.7)\end{array}$ & $\begin{array}{l}5.2 \\
(2.4-11.2)\end{array}$ & $\begin{array}{l}0.2 \\
(0.1-0.4)\end{array}$ & $\begin{array}{l}27.2 \\
(8.5-86.6)\end{array}$ \\
\hline & Barra et al. ${ }^{\mathrm{a}}[23]$ & 301 & $\begin{array}{l}{[\mathrm{TA}] 81 \%} \\
(69-89)\end{array}$ & $\begin{array}{l}{[\mathrm{TA}] 74 \%} \\
(55-86)\end{array}$ & NR & NR & NR \\
\hline & 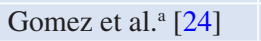 & 210 & NR & NR & NR & NR & NR \\
\hline & Lee et al. ${ }^{a}[25]$ & 298 & $\begin{array}{l}88 \% \\
(79-93)\end{array}$ & $\begin{array}{l}81 \% \\
(64-91)\end{array}$ & $\begin{array}{l}4.5 \\
(2.2-9.5)\end{array}$ & $\begin{array}{l}0.15 \\
(0.08-0.29)\end{array}$ & $\begin{array}{l}30 \\
(8-107)\end{array}$ \\
\hline \multirow[t]{3}{*}{$\begin{array}{l}\text { Infective } \\
\text { endocarditis }\end{array}$} & Yan et al. [30] & 246 & $\begin{array}{l}61 \% \\
(52-88)\end{array}$ & $\begin{array}{l}88 \% \\
(80-93)\end{array}$ & $\begin{array}{l}3.24 \\
(1.67-6.28)\end{array}$ & $\begin{array}{l}0.5 \\
(0.32-0.77)\end{array}$ & $\begin{array}{l}6.98 \\
(2.5-19.1)\end{array}$ \\
\hline & Mahmood et al. [31] & 537 & $\begin{array}{l}76.8 \% \\
(71.8-81.4)\end{array}$ & $\begin{array}{l}77.9 \% \\
(71.9-83.2)\end{array}$ & NR & NR & NR \\
\hline & Juneau et al. [32] & 329 & $\begin{array}{l}81 \% \\
(73-86)\end{array}$ & $\begin{array}{l}85 \% \\
(78-91)\end{array}$ & NR & NR & NR \\
\hline \multirow[t]{2}{*}{ CIED infections } & Mahmood et al. [33] & 492 & $\begin{array}{l}85 \% \\
(80-89)\end{array}$ & $\begin{array}{l}90 \% \\
(84-94)\end{array}$ & NR & NR & NR \\
\hline & Juneau et al. [34] & 331 & $\begin{array}{l}87 \% \\
(82-91)\end{array}$ & $\begin{array}{l}94 \% \\
(88-98)\end{array}$ & NR & NR & NR \\
\hline \multirow[t]{2}{*}{$\begin{array}{l}\text { Vascular graft } \\
\text { infection }\end{array}$} & $\begin{array}{l}\text { Reinders Folmer } \\
\text { et al. [36] }\end{array}$ & 144 & $\begin{array}{l}95 \% \\
(87-99)\end{array}$ & $\begin{array}{l}80 \% \\
(69-89)\end{array}$ & NR & NR & $\begin{array}{l}38 \\
(8.5-170)\end{array}$ \\
\hline & Rojoa et al. [37] & NR & $\begin{array}{l}97 \% \\
(89-99)\end{array}$ & $\begin{array}{l}89 \% \\
(70-96)\end{array}$ & NR & NR & NR \\
\hline \multirow[t]{3}{*}{$\begin{array}{l}\text { Cardiac } \\
\text { sarcoidosis }\end{array}$} & Youssef et al. ${ }^{\mathrm{a}}$ [42] & 164 & $\begin{array}{l}89 \% \\
(79-96)\end{array}$ & $\begin{array}{l}78 \% \\
(68-86)\end{array}$ & $\begin{array}{l}4.1 \\
(1.7-10)\end{array}$ & $\begin{array}{l}0.19 \\
(0.1-0.4)\end{array}$ & $\begin{array}{l}25.6 \\
(7.3-89.5)\end{array}$ \\
\hline & Tang et al. ${ }^{\mathrm{a}}$ [43] & 559 & $\begin{array}{l}75 \% \\
(69-80)\end{array}$ & $\begin{array}{l}81 \% \\
(76-85)\end{array}$ & NR & NR & $\begin{array}{l}16.9 \\
(7.6-37.5)\end{array}$ \\
\hline & Kim et al. ${ }^{a}[44]$ & 891 & $\begin{array}{l}84 \% \\
(71-91)\end{array}$ & $\begin{array}{l}83 \% \\
(74-89)\end{array}$ & $\begin{array}{l}4.9 \\
(3.3-7.3)\end{array}$ & $\begin{array}{l}0.2 \\
(0.11-0.35)\end{array}$ & $\begin{array}{l}27 \\
(14-55)\end{array}$ \\
\hline Osteomyelitis & Wang et al. ${ }^{\mathrm{a}}$ [46] & 319 & $\begin{array}{l}92.3 \% \\
(86.7-96.1)\end{array}$ & $\begin{array}{l}92 \% \\
(87-95.6)\end{array}$ & $\begin{array}{l}9.8 \\
(6-16)\end{array}$ & $\begin{array}{l}0.11 \\
(0.07-0.2)\end{array}$ & $\begin{array}{l}98 \\
(42.8-224)\end{array}$ \\
\hline
\end{tabular}


Table 12.1 (continued)

\begin{tabular}{|c|c|c|c|c|c|c|c|}
\hline Topic & Authors & $\begin{array}{l}\text { Patients } \\
\text { included }\end{array}$ & $\begin{array}{l}\text { Sensitivity } \\
(95 \% \mathrm{CI})\end{array}$ & $\begin{array}{l}\text { Specificity } \\
(95 \% \mathrm{CI})\end{array}$ & $\begin{array}{l}\mathrm{LR}+ \\
(95 \% \mathrm{CI})\end{array}$ & $\begin{array}{l}\mathrm{LR}- \\
(95 \% \mathrm{CI})\end{array}$ & $\begin{array}{l}\text { DOR } \\
(95 \% \mathrm{CI})\end{array}$ \\
\hline \multirow{2}{*}{$\begin{array}{l}\text { Osteomyelitis } \\
\text { related to } \\
\text { diabetic foot }\end{array}$} & Treglia et al. ${ }^{\mathrm{a}}$ [47] & 178 & $\begin{array}{l}74 \% \\
(60-85)\end{array}$ & $\begin{array}{l}91 \% \\
(85-96)\end{array}$ & $\begin{array}{l}5.6 \\
(2-15.3)\end{array}$ & $\begin{array}{l}0.37 \\
(0.1-1.35)\end{array}$ & $\begin{array}{l}16.9 \\
(2-139.6)\end{array}$ \\
\hline & Lauri et al. ${ }^{\mathrm{a}}$ [48] & 254 & $\begin{array}{l}89 \% \\
(68-97)\end{array}$ & $\begin{array}{l}92 \% \\
(85-96)\end{array}$ & $\begin{array}{l}11 \\
(4.7-25)\end{array}$ & $\begin{array}{l}0.11 \\
(0.03-0.4)\end{array}$ & $\begin{array}{l}95 \\
(18-504)\end{array}$ \\
\hline \multirow[t]{3}{*}{$\begin{array}{l}\text { Prosthetic joint } \\
\text { infection }\end{array}$} & Jin et al. ${ }^{\mathrm{a}}$ [49] & 838 & $\begin{array}{l}86 \% \\
(82-90)\end{array}$ & $\begin{array}{l}86 \% \\
83-89\end{array}$ & NR & NR & NR \\
\hline & Verberne et al. ${ }^{\mathrm{a}}[50]$ & 666 & $\begin{array}{l}86 \% \\
(80-90)\end{array}$ & $\begin{array}{l}93 \% \\
(90-95)\end{array}$ & NR & NR & NR \\
\hline & Verberne et al. ${ }^{\mathrm{a}}[51]$ & 179 & $\begin{array}{l}70 \% \\
(56-81)\end{array}$ & $\begin{array}{l}84 \% \\
(76-90)\end{array}$ & NR & NR & NR \\
\hline \multirow[t]{3}{*}{ Spondylodiscitis } & $\begin{array}{l}\text { Prodromou et al. } \\
{[52]}\end{array}$ & 224 & $\begin{array}{l}97 \% \\
(83-100)\end{array}$ & $\begin{array}{l}88 \% \\
(74-95)\end{array}$ & $\begin{array}{l}8.2 \\
(3.5-18.9)\end{array}$ & $\begin{array}{l}0.03 \\
(0-0.21)\end{array}$ & NR \\
\hline & Yin et al. ${ }^{\mathrm{a}}[53]$ & 191 & $\begin{array}{l}96 \% \\
(84-99)\end{array}$ & $\begin{array}{l}90 \% \\
(79-96)\end{array}$ & $\begin{array}{l}9.8 \\
(4.4-22)\end{array}$ & $\begin{array}{l}0.05 \\
(0.01-0.19)\end{array}$ & $\begin{array}{l}124 \\
(39-394)\end{array}$ \\
\hline & Kim et al. ${ }^{\mathrm{a}}[54]$ & 212 & $\begin{array}{l}95 \% \\
(87-98)\end{array}$ & $\begin{array}{l}88 \% \\
(73-95)\end{array}$ & $\begin{array}{l}7.6 \\
(3.4-17.2)\end{array}$ & $\begin{array}{l}0.05 \\
(0.02-0.14)\end{array}$ & $\begin{array}{l}141 \\
(44-444)\end{array}$ \\
\hline $\begin{array}{l}\text { Rheumatic } \\
\text { diseases }\end{array}$ & $\begin{array}{l}\text { Descamps et al. } \\
{[57]}\end{array}$ & 2300 & NR & NR & NR & NR & NR \\
\hline \multirow[t]{2}{*}{$\begin{array}{l}\text { Inflammatory } \\
\text { bowel diseases }\end{array}$} & Treglia et al. ${ }^{\mathrm{a}}[59]$ & 219 & $\begin{array}{l}85 \% \\
(81-88)\end{array}$ & $\begin{array}{l}87 \% \\
(84-90)\end{array}$ & $\begin{array}{l}6.2 \\
(2.9-13.4)\end{array}$ & $\begin{array}{l}0.19 \\
(0.1-0.34)\end{array}$ & $\begin{array}{l}44.3 \\
(11.8-167)\end{array}$ \\
\hline & Zhang et al. ${ }^{\mathrm{a}}[60]$ & 162 & $\begin{array}{l}84 \% \\
(78-89)\end{array}$ & $\begin{array}{l}86 \% \\
(81-89)\end{array}$ & $\begin{array}{l}5.3 \\
(1.3-22)\end{array}$ & $\begin{array}{l}0.2 \\
(0.07-0.6)\end{array}$ & $\begin{array}{l}25.9 \\
(2.8-238)\end{array}$ \\
\hline
\end{tabular}

$L R+$ positive likelihood ratio, $L R-$ negative likelihood ratio, DOR diagnostic odds ratio, $95 \% C I 95 \%$ confidence interval, $N R$ not reported, CIED cardiovascular implantable electronic device, GCA giant cell arteritis, TA Takayasu arteritis, $\mathrm{TA}^{+}$Takayasu arteritis using National Health Institute scale ${ }^{a}$ Both PET and PET/CT are included

Dong et al. firstly reported that the pooled sensitivity and specificity of ${ }^{18} \mathrm{~F}$-FDG PET/CT for the detection of FUO were 98.2\% (95\%CI: 93.699.8) and $85.9 \%$ (95\%CI: 75-93.4), respectively. Therefore, this method should be considered among the first diagnostic tools for patients with FUO in whom conventional diagnostics have been unsuccessful [7].

Hao et al. confirmed the high sensitivity of ${ }^{18} \mathrm{~F}$-FDG PET/CT for the diagnosis of patients with FUO (pooled value: $88 \%$; 95\%CI: $81-88$ ), but the possibility of false positive results should be kept in mind [8].

Another meta-analysis demonstrated that abnormal ${ }^{18} \mathrm{~F}$-FDG PET/CT findings are associated with a substantially increased final diagnostic rate in FUO (pooled odds ratio: 8.94; 95\% CI: $4.18-19.12, p<0.00001)$. Consequently, ${ }^{18} \mathrm{~F}-$ FDG PET/CT could be considered for inclusion in the first-line diagnostic workup of FUO [9].

Tateuchi et al. reported that ${ }^{18} \mathrm{~F}-\mathrm{FDG}$ PET/CT can be useful in identifying the source of fever in patients with classic FUO (immunocompetent patients). The summary sensitivity and specificity were $86 \%$ (95\%CI: 81-90) and 52\% (95\%CI: 36-67), respectively. The contribution of ${ }^{18} \mathrm{~F}-$ FDG PET/CT may be limited in clinical settings in which infectious and neoplastic causes are less common. Indirect comparisons of test performance suggested that ${ }^{18} \mathrm{~F}$-FDG PET/CT outperformed standalone ${ }^{18}$ F-FDG PET, Gallium-67 scintigraphy, and radiolabelled leukocyte scintigraphy in detecting causes of FUO. Studies using standardized diagnostic algorithms are needed to determine the optimal timing for testing and to assess the impact of tests on management decisions and patient-relevant outcomes [10].

Recently, Bharucha et al. reported an overall diagnostic contribution of 56\% (95\% CI: 50-61) of ${ }^{18} \mathrm{~F}-\mathrm{FDG}$ PET/CT in all patients with FUO. In a subgroup analysis taking into account previous investigations the diagnostic yield/added contribution of ${ }^{18} \mathrm{~F}$-FDG PET/CT over CT was $32 \%$ (95\%CI: 22-44). The pooled proportion of 
abnormal ${ }^{18} \mathrm{~F}$-FDG-PET/CT in patients with FUO was 69\% (95\%CI: 63-75); the higher proportion of abnormal scans was accounted for by a proportion of false positive abnormal scans with no contribution to the final diagnosis, with an overall result of 9\% (95\%CI: 5-14). The authors concluded that there is insufficient evidence to support the value of ${ }^{18} \mathrm{~F}$-FDG PET/CT in investigative algorithms of FUO [11].

Conversely, in an updated meta-analysis on patients with FUO or inflammation of unknown origin (IUO), ${ }^{18} \mathrm{~F}-\mathrm{FDG}$ PET/CT was demonstrated to be very helpful for recognizing and excluding diseases, directing further diagnostic decisions, and avoiding unnecessary invasive examinations. The pooled sensitivity and specificity were $84 \%$ (95\%CI: 79-89) and 63\% (95\%CI: 49-75), respectively. Based on these findings, the authors recommended ${ }^{18} \mathrm{~F}-\mathrm{FDG}$ PET/CT among the first-line diagnostic tools for patients with FUO and IUO [12].

Lastly, it has been recently demonstrated that patients with negative ${ }^{18} \mathrm{~F}-\mathrm{FDG}$ PET/CT results were significantly more likely to present with spontaneous fever regression than those with positive ${ }^{18} \mathrm{~F}$-FDG PET/CT results (summary relative risk $=5.6$ : 95\%CI: 3.4-9.2; $p<0.001$ ) [13].

Overall, there is not agreement among the selected meta-analyses about the added value of ${ }^{18} \mathrm{~F}-\mathrm{FDG}$ PET/CT in patients with FUO. The main drawback of the meta-analyses evaluating the diagnostic performance of ${ }^{18} \mathrm{~F}-\mathrm{FDG}$ PET/CT for this specific indication is that they include articles without real FUO patients or with highly variable definitions of FUO; therefore, related meta-analyses could be not accurate in this regard [14].

\subsection{Large Vessel Vasculitis (LVV)}

Large vessel vasculitis (LVV) is defined as an inflammatory disease mainly affecting the large arteries, with two major variants, Takayasu arteritis (TA) and giant cell arteritis (GCA). GCA often coexists with polymyalgia rheumatica (PMR) in the same patient, since both belong to the same disease spectrum [15]. ${ }^{18}$ F-FDG PET/ CT may demonstrate increased radiopharmaceu- tical uptake in the vascular wall of large vessels in patients with LVV; therefore, this method may be used for diagnosis, monitoring of disease activity, and evaluating disease progression in LVV [15-18], and several meta-analyses have assessed the role of this imaging method in this setting [19-25].

First meta-analyses including both ${ }^{18} \mathrm{~F}-\mathrm{FDG}$ PET and PET/CT studies reported a valuable diagnostic performance of these methods in patients with GCA with a pooled sensitivity and specificity of $80 \%$ (95\%CI: 63-91) and 89\% (95\%CI: 78-94), respectively [19], and a moderate value of these methods in assessing TA activity, with a pooled sensitivity and specificity of $70.1 \%$ (95\%CI: 58.6-80) and 77.2\% (95\%CI: 64.2-87.3), respectively [20].

In a meta-analysis of Soussan et al. including both ${ }^{18} \mathrm{~F}$-FDG PET and PET/CT studies, these imaging methods showed good performances in the diagnosis of LVV, with higher accuracy in GCA patients than in TA patients. A vascular uptake equal to or higher than the liver uptake appeared to be a good criterion for the diagnosis of vascular inflammation. ${ }^{18} \mathrm{~F}-\mathrm{FDG}$ PET or PET/ CT showed high sensitivity and specificity for the diagnosis of LVV in GCA patients in comparison to controls, with pooled values of $90 \%$ (95\% CI: 79-93) and 98\% (95\%CI: 94-99), respectively. ${ }^{18} \mathrm{~F}-\mathrm{FDG}$ PET or PET/CT had a pooled sensitivity of $87 \%$ (95\%CI: 78-93) and specificity of $73 \%$ (95\%CI: 63-81) for the assessment of disease activity in TA, with up to $84 \%$ of specificity in studies using National Institutes of Health criteria as the disease activity assessment scale [21].

Another meta-analysis by Lee et al. confirmed that ${ }^{18}$ F-FDG PET/CT has good diagnostic accuracy for LVV with a pooled sensitivity and specificity of $83.9 \%$ (95\%CI: 71.7-92.4) and $87.2 \%$ (95\%CI: 72.6-95.7), respectively [22].

In a recent meta-analysis, the pooled sensitivity and specificity of ${ }^{18} \mathrm{~F}$-FDG PET or PET/CT for detecting active disease in TA compared to clinical assessment were 81\% (95\%CI: 69-89) and 74\% (95\%CI: 55-86), respectively. Active disease by ${ }^{18} \mathrm{~F}-\mathrm{FDG}$ PET or PET/CT was also associated with elevations of acute phase reactants, as C-reactive protein (CRP) and erythrocyte sedimentation rate (ESR) [23]. Conversely, 
in another meta-analysis by Gomez et al. about the association between the CRP value and ${ }^{18} \mathrm{~F}$ FDG PET or PET/CT vascular positivity in TA, CRP concentration only moderately reflected the ${ }^{18} \mathrm{~F}-\mathrm{FDG}$ PET vascular positivity in TA, suggesting dissociated information [24]. More prospective studies are needed to assess the value of ${ }^{18} \mathrm{~F}-\mathrm{FDG}$ PET/CT as an independent biomarker for subtle vascular wall inflammation detection in patients with TA [24].

Lastly, an updated meta-analysis confirmed that ${ }^{18} \mathrm{~F}-\mathrm{FDG}$ PET or PET/CT has a good performance for the detection of active disease in patients with LVV with a pooled sensitivity and specificity of $88 \%$ (95\%CI: 79-93) and $81 \%$ (95\%CI: 64-91), respectively. Therefore, ${ }^{18} \mathrm{~F}-$ FDG PET/CT could be suggested as a surrogate biomarker for assessment of disease activity of LVV during or after immunosuppressive therapy, but further studies are warranted to determine if PET-based treatment of LVV can improve outcomes [25].

Several factors may significantly influence the diagnostic performance of ${ }^{18} \mathrm{~F}$-FDG PET/CT in LVV including different PET interpretation criteria, atherosclerotic vascular ${ }^{18} \mathrm{~F}-\mathrm{FDG}$ uptake (a possible source of false positive findings), and immunosuppressive therapy (a possible source of false findings) [15].

Overall, based on the available evidence, ${ }^{18} \mathrm{~F}$ FDG PET/CT has demonstrated high diagnostic performance for the detection of LVV. Further studies are needed to select the most clinically relevant and reproducible criteria for defining the presence of LVV with ${ }^{18} \mathrm{~F}-\mathrm{FDG}$ PET/CT, as well as to test the clinical impact of ${ }^{18} \mathrm{~F}-\mathrm{FDG}$ PET/CT on the management of patients with suspected LVV [15].

\subsection{Infectious Endocarditis and Cardiovascular Implantable Electronic Device Infections}

Infectious endocarditis (IE) is a serious and potentially life-threatening condition. The current diagnosis of IE is based on the modified Duke criteria, which has approximately $80 \%$ sen- sitivity for the diagnosis of native valve endocarditis (NVE), with lower sensitivity for the diagnosis of prosthetic valve endocarditis (PVE) and culture-negative endocarditis [26, 27]. Noninvasive imaging modalities may improve diagnosis of infective endocarditis (IE) [26, 27]. In particular, ${ }^{18} \mathrm{~F}$-FDG PET/CT is currently included as diagnostic tool in the diagnostic flow chart for IE [26-29] and some meta-analyses have evaluated the diagnostic performance of this method in patients with IE or CIED infections [30-34].

A first meta-analysis published in 2016 demonstrated that the overall diagnostic performance of ${ }^{18} \mathrm{~F}-\mathrm{FDG}$ PET/CT for the diagnosis of IE was not high due to the low sensitivity: pooled sensitivity and specificity were $61 \%$ (95\%CI: 52-88) and 88\% (95\%CI: 80-93), respectively. However, the diagnostic performance of ${ }^{18} \mathrm{~F}-\mathrm{FDG}$ PET/CT increased in the subgroup of patients with PVE [30].

Mahmood et al. demonstrated that ${ }^{18} \mathrm{~F}-\mathrm{FDG}$ $\mathrm{PET} / \mathrm{CT}$ may be a useful adjunctive diagnostic tool in the evaluation of diagnostically challenging cases of IE, particularly in PVE. The pooled sensitivity and specificity of ${ }^{18} \mathrm{~F}-\mathrm{FDG}$ PET/CT for diagnosis of IE were $76.8 \%$ (95\%CI: 71.881.4 ) and $77.9 \%$ (95\%CI: 71.9-83.2), respectively. Diagnostic accuracy was improved for PVE with pooled sensitivity of $80.5 \%$ (95\%CI: $74.1-86)$ and pooled specificity of $73.1 \%$ (95\%CI: 63.8-81.2). More recent studies published from 2015 to 2017 reported a higher pooled sensitivity of $81.3 \%$ (95\%CI: 74.3-87) and specificity of $79 \%$ (95\%CI: 71.2-85.5). The majority of the recent studies were prospective and used a specific protocol (i.e., a lowcarbohydrate fat-allowed diet for at least $24 \mathrm{~h}$ prior to imaging, a prolonged fasting prior to imaging, and/or an intravenous heparin bolus prior to ${ }^{18} \mathrm{~F}$-FDG administration). ${ }^{18} \mathrm{~F}$-FDG PET/ CT also has the potential to detect clinically relevant extra-cardiac foci of infection, malignancy, and other sources of inflammation, leading to more appropriate treatment regimens and surgical intervention. Additional extra-cardiac foci of infection were found on $17 \%$ of patients in this meta-analysis [31].

In another meta-analysis, Juneau et al. demonstrated that ${ }^{18} \mathrm{~F}-\mathrm{FDG}$ PET/CT has a good diag- 
nostic accuracy for the diagnosis of IE if adequate patient preparation for suppression of physiological myocardial ${ }^{18} \mathrm{~F}$-FDG uptake was performed, including prolonged fasting at least $12 \mathrm{~h}$ and/or heparin injection before ${ }^{18} \mathrm{~F}-\mathrm{FDG}$ administration, and/or high-fat carbohydrate-restricted proteinpermitted diet (minimum two meals for $24 \mathrm{~h}$ ). Pooled sensitivity of ${ }^{18} \mathrm{~F}$-FDG PET/CT performed with adequate cardiac preparation for the diagnosis of IE was $81 \%$ (95\% CI: 73-86) and pooled specificity was $85 \%$ (95\%CI: $78-91)$. In the subgroup of patients with PVE, the pooled sensitivity was $85 \%$ (95\%CI: 77-91) but specificity was $81 \%$ (95\%CI: 72-88). Therefore, ${ }^{18} \mathrm{~F}-$ FDG PET/CT may be useful in the investigation of IE, and should be considered in cases where the diagnosis is uncertain [32].

${ }^{18} \mathrm{~F}$-FDG PET/CT may be helpful in the diagnosis of cardiovascular implantable electronic device (CIED) infections, particularly in patients with the absence of localizing signs or definitive echocardiographic findings. In a recent metaanalysis, Mahmood et al. reported a pooled sensitivity and specificity of ${ }^{18} \mathrm{~F}$-FDG PET/CT in the diagnosis of CIED infections of $85 \%$ (95\% CI: 80-89) and 90\% (95\%CI: 84-94), respectively. ${ }^{18} \mathrm{~F}-\mathrm{FDG}$ PET/CT demonstrated a higher sensitivity of 96\% (95\%CI: 86-99) and specificity of 97\% (95\%CI: 86-99) for diagnosis of pocket infections. Diagnostic accuracy for lead infections or CIED-IE was lower with pooled sensitivity of $76 \%$ (95\% CI: 65-85) and specificity of $83 \%$ (95\% CI: 72-90). In the subgroup of studies that described the use of any myocardial suppression protocol, the pooled sensitivity was $92 \%$ (95\%CI: 85-96) and the pooled specificity was 81\% (95\%CI: 71-89) [33].

Another recent meta-analysis confirmed the high diagnostic performance of ${ }^{18}$ F-FDG PET/ $\mathrm{CT}$ for the diagnosis of CIED infections with a pooled sensitivity of $87 \%$ (95\%CI: 82-91) and a pooled specificity of $94 \%$ (95\%CI: 88-98). Pooled sensitivity and specificity for diagnosis of pocket/generator related CIED infections were 93\% (95\%CI: 84-98) and 98\% (95\%CI: 88-100), respectively. Pooled sensitivity and specificity for diagnosis of lead or IE-related CIED infection were 65\% (95\%CI: 53-76) and 88\% (95\%CI: 77-94), respectively [34].
Overall, ${ }^{18} \mathrm{~F}-\mathrm{FDG}$ PET/CT demonstrated a good diagnostic performance in patients with IE and CIED infections with higher diagnostic accuracy if adequate patient preparation for suppression of physiological myocardial ${ }^{18} \mathrm{~F}-\mathrm{FDG}$ uptake was performed.

\subsection{Vascular Graft Infections}

Vascular graft infection (VGI), a serious complication in vascular surgery, has a high morbidity and mortality rate. The diagnosis is complicated by non-specific symptoms and challenged by the variable accuracy of different imaging techniques $[35,36]$. A recent meta-analysis demonstrated a good diagnostic performance of ${ }^{18} \mathrm{~F}-\mathrm{FDG}$ PET/ $\mathrm{CT}$ in patients with VGI with a pooled sensitivity and specificity of 95\% (95\%CI: 87-99) and 80\% (95\%CI: 69-89), respectively [36].

Another recent meta-analysis investigating the diagnostic accuracy of ${ }^{18} \mathrm{~F}$-FDG PET/CT in VGI reported a pooled sensitivity and specificity for focal ${ }^{18} \mathrm{~F}-\mathrm{FDG}$ uptake of $97 \%$ (95\%CI: 89-99) and $89 \%$ (95\%CI: 70-96), respectively [37].

Factors influencing the diagnostic performance of ${ }^{18} \mathrm{~F}$-FDG PET/CT in VGI include the time at which ${ }^{18} \mathrm{~F}$-FDG PET/CT is performed after surgery (if ${ }^{18} \mathrm{~F}-\mathrm{FDG} \mathrm{PET} / \mathrm{CT}$ is performed in cases of recently implanted grafts, false positive ${ }^{18} \mathrm{~F}$-FDG PET/CT findings for VGI are possible), the use of antibiotics prior to ${ }^{18} \mathrm{~F}-\mathrm{FDG}$ PET/CT (causing possible false negative findings for VGI), and the PET interpretation criteria used [37].

\subsection{Sarcoidosis}

Sarcoidosis is a multisystem chronic inflammatory disease of unknown etiology characterized by widespread growth of non-caseating granulomas. The diagnosis of sarcoidosis is based on clinical and imaging presentation, histological confirmation, and the absence of alternative diseases. Imaging techniques may play a role in the diagnostic workup of patients with sarcoidosis to assess disease extent and activity, and treatment response evaluation [38]. The role of ${ }^{18} \mathrm{~F}-\mathrm{FDG}$ 
PET/CT in patients with sarcoidosis is well established [39, 40]. Based on evidence-based data, the recommendations for use of ${ }^{18} \mathrm{~F}-\mathrm{FDG}$ PET/CT in patients with sarcoidosis could be the following: evaluation of inflammatory active disease in patients with persistent symptoms and negative serologic markers; assessment of inflammation in radiologic stage IV sarcoidosis with lung fibrosis; evaluation of inflammatory active extrathoracic sites of sarcoidosis or assessment of cardiac sarcoidosis (especially in patients with implanted pacemakers); identification of active sites for diagnostic biopsy not revealed by other methods; evaluation of treatment response in refractory sarcoidosis [39].

The role of ${ }^{18} \mathrm{~F}-\mathrm{FDG}$ PET/CT in cardiac sarcoidosis is currently under active investigation [41] and some meta-analyses have addressed the diagnostic performance of ${ }^{18} \mathrm{~F}$-FDG PET/CT in this setting [42-44].

In the meta-analysis of Youssef et al., the pooled sensitivity and specificity of ${ }^{18} \mathrm{~F}-\mathrm{FDG}$ PET or PET/CT for diagnosis of cardiac sarcoidosis were 89\% (95\%CI: 79-96) and 78\% (95\%CI: 68-86), respectively [42].

Tang et al. demonstrated that the diagnostic accuracy of ${ }^{18} \mathrm{~F}-\mathrm{FDG}$ PET/CT for cardiac sarcoidosis depends on adequate suppression of physiological cardiac glucose uptake. Overall, ${ }^{18} \mathrm{~F}-\mathrm{FDG}$ PET/CT had a pooled sensitivity of 75\% (95\%CI: 69-80) and a pooled specificity of 81\% (95\% CI: 76-85) for the diagnosis of cardiac sarcoidosis. This modest diagnostic accuracy was attributed to the inclusion of studies in which a short fasting duration before scanning likely influenced its sensitivity. Excluding studies without adequate myocardial suppression resulted in a pooled sensitivity of $81 \%$ (95\%CI: 76-86) and a pooled specificity of $82 \%$ (95\%CI: 77-86). Fasting for at least $12 \mathrm{~h}$ before scanning or a high-fat low-carbohydrate diet given at 3-6 h before imaging or heparin infusion before imaging has shown to improve the diagnostic accuracy of ${ }^{18}$ F-FDG PET/CT in cardiac sarcoidosis [43].

Lastly, an updated meta-analysis on the diagnostic performance of ${ }^{18} \mathrm{~F}$-FDG PET or PET/CT in cardiac sarcoidosis demonstrated a pooled sensitivity and specificity of $84 \%$ (95\%CI: 71-91) and $83 \%$ (95\% CI: 74-89), respectively. The pres- ence of combined myocardial perfusion imaging improved the diagnostic accuracy of ${ }^{18} \mathrm{~F}-\mathrm{FDG}$ PET/CT for diagnosis of cardiac sarcoidosis. Nevertheless further large multicenter studies in this setting are needed [44].

\subsection{Musculoskeletal Infections}

Timely identification and precise localization of musculoskeletal infections by imaging techniques are critical for early initiation of treatment and can have a significant impact on patient outcome. In this setting, nuclear medicine and radiological imaging are complementary techniques [45]. In particular, several meta-analyses have investigated the diagnostic performance of ${ }^{18} \mathrm{~F}$ FDG PET/CT in patients with suspicious musculoskeletal infections [46-54].

Wang et al. calculated the diagnostic performance of ${ }^{18} \mathrm{~F}$-FDG PET or PET/CT in patients with suspicious osteomyelitis reporting a high pooled sensitivity and specificity in this setting: pooled values were $92.3 \%$ (95\%CI: 86.7-96.1) and 92\% (95\%CI: 87-95.6), respectively [46].

A first meta-analysis focused on the diagnostic performance of ${ }^{18} \mathrm{~F}-\mathrm{FDG}$ PET or PET/CT in osteomyelitis related to diabetic foot reported a pooled sensitivity and specificity of $74 \%$ (95\% CI: 60-85) and 91\% (95\%CI: 85-96), respectively [47]. An updated meta-analysis on the same topic demonstrated a pooled sensitivity of $89 \%$ (95\%CI: 68-97) and a pooled specificity of $92 \%$ (95\%CI: 85-96) [48].

Jin et al. calculated the diagnostic performance of ${ }^{18} \mathrm{~F}$-FDG PET or PET/CT in detecting prosthetic infection after arthroplasty. They found a pooled sensitivity and specificity of $86 \%$ (95\%CI: 82-90) and 86\% (95\%CI: 83-89), respectively. The pooled sensitivity of ${ }^{18} \mathrm{~F}-\mathrm{FDG}$ PET or PET/CT in demonstrating hip and knee prosthetic infection was $88 \%$ (95\%CI: 83-92) and $72 \%$ (95\%CI: 58-84), respectively. The pooled specificity of ${ }^{18} \mathrm{~F}$-FDG PET or PET/CT in demonstrating hip and knee prosthetic infection was 88\% (95\%CI: 84-91) and 80\% (95\% CI: 71-88), respectively [49].

A meta-analysis focused on periprosthetic hip infection confirmed the good diagnostic accuracy 
of ${ }^{18} \mathrm{~F}$-FDG PET or PET/CT in this setting with pooled sensitivity and specificity of $86 \%$ (95\%CI: 80-90) and 93\% (95\%CI: 90-95), respectively, using increased ${ }^{18} \mathrm{~F}-\mathrm{FDG}$ uptake in the boneprosthesis interface as the criterion for infection for the index test [50].

A meta-analysis focused on periprosthetic knee infection demonstrated a nonoptimal diagnostic accuracy of ${ }^{18} \mathrm{~F}$-FDG PET or PET/CT in this setting with pooled sensitivity and specificity of 70\% (95\%CI: 56-81) and 84\% (95\% CI: 76-90) [51].

Some factors influencing the diagnostic performance of ${ }^{18} \mathrm{~F}$-FDG PET/CT in patients with osteomyelitis should be underlined: first of all, several interpretation criteria of ${ }^{18} \mathrm{~F}$-FDG PET have been used in the literature, by using visual and/or semi-quantitative criteria, leading to different diagnostic accuracy values [46-51]. Furthermore, continuous physiologic ${ }^{18} \mathrm{~F}-\mathrm{FDG}$ activity around the prostheses may be cause of false positive ${ }^{18} \mathrm{~F}-\mathrm{FDG}$ PET/CT findings for periprosthetic infection [49-51].

${ }^{18}$ F-FDG PET or PET/CT has an excellent diagnostic performance in detecting infectious spondylodiscitis [55]. A first meta-analysis on ${ }^{18}$ F-FDG PET or PET/CT in patients with suspicious spondylodiscitis reported a pooled sensitivity and specificity of $97 \%$ (95\%CI: 83-100) and 88\% (95\% CI: 74-95), respectively [52]. In this setting, the diagnostic performance of ${ }^{18} \mathrm{~F}$-FDG PET or PET/CT was higher compared with magnetic resonance imaging (MRI). Considering studies comparing ${ }^{18} \mathrm{~F}$-FDG PET or PET/CT and MRI, pooled sensitivity and specificity of ${ }^{18} \mathrm{~F}-$ FDG PET or PET/CT were 96\% (95\%CI: 84-99) and 90\% (95\%CI: 79-96), whereas the pooled sensitivity and specificity of MRI were $76 \%$ (95\%CI: 65-84) and 62\% (95\%CI: 45-77) [53]. Another recent meta-analysis confirmed the better diagnostic accuracy of ${ }^{18} \mathrm{~F}$-FDG PET or PET/ CT compared to MRI for the detection of spondylodiscitis: for ${ }^{18} \mathrm{~F}-\mathrm{FDG}$ PET or PET/CT, pooled sensitivity and specificity were 95\% (95\%CI: 87-98) and 88\% (95\%CI: 73-95), respectively; for MRI, pooled sensitivity and specificity were 85\% (95\%CI: 65-95) and 66\% (95\%CI: 48-80), respectively [54].
Overall, based on the available evidence, ${ }^{18}$ F-FDG PET/CT has demonstrated a good diagnostic performance for the detection of musculoskeletal infections.

\subsection{Inflammatory Rheumatic Diseases}

Molecular imaging methods, including ${ }^{18} \mathrm{~F}-\mathrm{FDG}$ PET/CT, have been proposed for a better assessment of inflammatory rheumatic diseases [56]. ${ }^{18} \mathrm{~F}$-FDG uptake in the shoulders or hips was often reported in PMR (pooled prevalence: 76\%), especially in periarticular sites (pooled prevalence: $84 \%$ ). Furthermore, interspinous ${ }^{18} \mathrm{~F}-\mathrm{FDG}$ uptake, demonstrating interspinous bursitis, is common in PMR (pooled prevalence: 67\%). However, these findings are not very specific for PMR [57].

Patients with rheumatoid arthritis (RA) may also have interspinous ${ }^{18} \mathrm{~F}-\mathrm{FDG}$ uptake (pooled prevalence: $34 \%$ ) or articular ${ }^{18} \mathrm{~F}-\mathrm{FDG}$ uptake in shoulders or hips (pooled prevalence: 66\%) or in other articular regions (pooled prevalence: $78 \%$ ). Articular ${ }^{18} \mathrm{~F}$-FDG uptake is not specific for PMR or RA, as it is common in other connective tissue diseases (pooled prevalence: $70 \%$ ). Overall, ${ }^{18} \mathrm{~F}$ FDG PET/CT is helpful in diagnostic research, but the interpretation of ${ }^{18} \mathrm{~F}-\mathrm{FDG}$ uptake at each site is not characteristic of a specific inflammatory rheumatic disease [57].

\subsection{Inflammatory Bowel Diseases}

${ }^{18}$ F-FDG PET/CT may also be used to image areas of active inflammation, such as those occurring in patients with active inflammatory bowel disease (IBD) as Crohn's disease and ulcerative colitis [58]. In this setting, ${ }^{18} \mathrm{~F}-\mathrm{FDG}$ PET or PET/CT showed a good accuracy with a pooled sensitivity and specificity of $85 \%$ (95\%CI: 81-88) and 87\% (95\%CI 84-90), respectively [59]. These findings were confirmed by another meta-analysis including prospective studies only [60]. Nevertheless, more prospec- 
tive studies evaluating the role of ${ }^{18} \mathrm{~F}-\mathrm{FDG}$ PET/ $\mathrm{CT}$ for this indication are needed. Specific challenges for the use of ${ }^{18} \mathrm{~F}-\mathrm{FDG}$ PET/CT in IBD are the physiological ${ }^{18} \mathrm{~F}-\mathrm{FDG}$ uptake in the bowel and the movement of the bowel that may influence a correct co-registration of ${ }^{18} \mathrm{~F}-\mathrm{FDG}$ PET and CT images [59].

\section{References}

1. Signore A, Anzola KL, Auletta S, Varani M, Petitti A, Pacilio M, et al. Current status of molecular imaging in inflammatory and autoimmune disorders. Curr Pharm Des. 2018;24(7):743-53.

2. Sollini M, Lauri C, Boni R, Lazzeri E, Erba PA, Signore A. Current status of molecular imaging in infections. Curr Pharm Des. 2018;24(7):754-71.

3. Jamar F, Buscombe J, Chiti A, Christian PE, Delbeke $\mathrm{D}$, Donohoe KJ, et al. EANM/SNMMI guideline for 18F-FDG use in inflammation and infection. J Nucl Med. 2013;54(4):647-58.

4. Meyer M, Testart N, Jreige M, Kamani C, Moshebah M, Muoio B, et al. Diagnostic performance of PET or PET/CT using (18)F-FDG labeled white blood cells in infectious diseases: a systematic review and a bivariate meta-analysis. Diagnostics. 2019;9(2):E60.

5. Treglia G. Diagnostic performance of (18)F-FDG $\mathrm{PET} / \mathrm{CT}$ in infectious and inflammatory diseases according to published meta-analyses. Contrast Media Mol Imaging. 2019;2019:3018349.

6. Kouijzer IJE, Mulders-Manders CM, Bleeker-Rovers CP, Oyen WJG. Fever of unknown origin: the value of FDG-PET/CT. Semin Nucl Med. 2018;48(2):100-7.

7. Dong MJ, Zhao K, Liu ZF, Wang GL, Yang SY, Zhou GJ. A meta-analysis of the value of fluorodeoxyglucose-PET/PET-CT in the evaluation of fever of unknown origin. Eur $\mathrm{J}$ Radiol. 2011;80(3):834-44.

8. Hao R, Yuan L, Kan Y, Li C, Yang J. Diagnostic performance of 18F-FDG PET/CT in patients with fever of unknown origin: a meta-analysis. Nucl Med Commun. 2013;34(7):682-8.

9. Besson FL, Chaumet-Riffaud P, Playe M, Noel N, Lambotte O, Goujard C, et al. Contribution of (18) F-FDG PET in the diagnostic assessment of fever of unknown origin (FUO): a stratification-based meta-analysis. Eur J Nucl Med Mol Imaging. 2016;43(10):1887-95.

10. Takeuchi M, Dahabreh IJ, Nihashi T, Iwata M, Varghese GM, Terasawa T. Nuclear imaging for classic fever of unknown origin: meta-analysis. J Nucl Med. 2016;57(12):1913-9.

11. Bharucha T, Rutherford A, Skeoch S, Alavi A, Brown M, Galloway J, FDG-PET/CT in fever of unknown origin working group. Diagnostic yield of FDG-PET/ $\mathrm{CT}$ in fever of unknown origin: a systematic review, meta-analysis, and Delphi exercise. Clin Radiol. 2017;72(9):764-71.

12. Kan Y, Wang W, Liu J, Yang J, Wang Z. Contribution of 18F-FDG PET/CT in a case-mix of fever of unknown origin and inflammation of unknown origin: a meta-analysis. Acta Radiol. 2019;60(6):716-25.

13. Takeuchi M, Nihashi T, Gafter-Gvili A, GarcíaGómez FJ, Andres E, Blockmans D, et al. Association of 18F-FDG PET or PET/CT results with spontaneous remission in classic fever of unknown origin: a systematic review and meta-analysis. Medicine. 2018;97(43):e12909.

14. Kouijzer IJE, van der Meer JWM, Oyen WJG, Bleeker-Rovers CP. Diagnostic yield of FDG-PET/ $\mathrm{CT}$ in fever of unknown origin: a systematic review, meta-analysis, and Delphi exercise. Clin Radiol. 2018;73(6):588-9.

15. Slart RHJA, Writing group, Reviewer group, Members of EANM Cardiovascular, Members of EANM Infection \& Inflammation, Members of Committees, SNMMI Cardiovascular, Members of Council, PET Interest Group, Members of ASNC, EANM Committee Coordinator. FDG-PET/CT(A) imaging in large vessel vasculitis and polymyalgia rheumatica: joint procedural recommendation of the EANM, SNMMI, and the PET Interest Group (PIG), and endorsed by the ASNC. Eur J Nucl Med Mol Imaging. 2018;45(7):1250-69.

16. Treglia G, Mattoli MV, Leccisotti L, Ferraccioli G, Giordano A. Usefulness of whole-body fluorine-18fluorodeoxyglucose positron emission tomography in patients with large-vessel vasculitis: a systematic review. Clin Rheumatol. 2011;30(10):1265-75.

17. Treglia G, Versari A, Giovanella L, Pipitone N, Salvarani C. Is 18F-FDG PET a 'potentially hazardous' or an effective tool in evaluating patients with large-vessel vasculitis? Clin Exp Rheumatol. 2013;31(1 Suppl 75):S93.

18. Dejaco C, Ramiro S, Duftner C, Besson FL, Bley TA, Blockmans D, et al. EULAR recommendations for the use of imaging in large vessel vasculitis in clinical practice. Ann Rheum Dis. 2018;77(5):636-43.

19. Besson FL, Parienti JJ, Bienvenu B, Prior JO, Costo $\mathrm{S}$, Bouvard G, et al. Diagnostic performance of ${ }^{18}$ F-fluorodeoxyglucose positron emission tomography in giant cell arteritis: a systematic review and meta-analysis. Eur J Nucl Med Mol Imaging. 2011;38(9):1764-72.

20. Cheng Y, Lv N, Wang Z, Chen B, Dang A. 18-FDGPET in assessing disease activity in Takayasu arteritis: a meta-analysis. Clin Exp Rheumatol. 2013;31(1 Suppl 75):S22-7.

21. Soussan M, Nicolas P, Schramm C, Katsahian S, Pop G, Fain O, et al. Management of large-vessel vasculitis with FDG-PET: a systematic literature review and meta-analysis. Medicine. 2015;94(14):e622.

22. Lee YH, Choi SJ, Ji JD, Song GG. Diagnostic accuracy of 18F-FDG PET or PET/CT for large vessel vasculitis: a meta-analysis. Z Rheumatol. 2016;75(9):924-31. 
23. Barra L, Kanji T, Malette J, Pagnoux C, CanVasc. Imaging modalities for the diagnosis and disease activity assessment of Takayasu's arteritis: a systematic review and meta-analysis. Autoimmun Rev. 2018;17(2):175-87.

24. Gomez L, Chaumet-Riffaud P, Noel N, Lambotte O, Goujard C, Durand E, et al. Effect of CRP value on (18)F-FDG PET vascular positivity in Takayasu arteritis: a systematic review and per-patient based meta-analysis. Eur J Nucl Med Mol Imaging. 2018;45(4):575-81.

25. Lee SW, Kim SJ, Seo Y, Jeong SY, Ahn BC, Lee J. F-18 FDG PET for assessment of disease activity of large vessel vasculitis: a systematic review and metaanalysis. J Nucl Cardiol. 2019;26(1):59-67.

26. Erba PA, Lancellotti P, Vilacosta I, Gaemperli O, Rouzet F, Hacker M, et al. Recommendations on nuclear and multimodality imaging in IE and CIED infections. Eur J Nucl Med Mol Imaging. 2018;45(10):1795-815.

27. Gomes A, Glaudemans AWJM, Touw DJ, van Melle JP, Willems TP, Maass AH, et al. Diagnostic value of imaging in infective endocarditis: a systematic review. Lancet Infect Dis. 2017;17(1):e1-e14.

28. Treglia G, Bertagna F. Factors influencing the sensitivity of 18F-FDG PET/CT in the detection of infective endocarditis. Eur $\mathrm{J}$ Nucl Med Mol Imaging. 2013;40(7):1112-3.

29. Caldarella C, Leccisotti L, Treglia G, Giordano A. Which is the optimal acquisition time for FDG PET/CT imaging in patients with infective endocarditis? J Nucl Cardiol. 2013;20(2):307-9.

30. Yan J, Zhang C, Niu Y, Yuan R, Zeng X, Ge X, et al. The role of 18F-FDG PET/CT in infectious endocarditis: a systematic review and meta-analysis. Int J Clin Pharmacol Ther. 2016;54(5):337-42.

31. Mahmood M, Kendi AT, Ajmal S, Farid S, O'Horo JC, Chareonthaitawee P, et al. Meta-analysis of 18F-FDG PET/CT in the diagnosis of infective endocarditis. J Nucl Cardiol. 2019;26(3):922-35.

32. Juneau D, Golfam M, Hazra S, Erthal F, Zuckier LS, Bernick J, et al. Molecular imaging for the diagnosis of infective endocarditis: a systematic literature review and meta-analysis. Int $\mathrm{J}$ Cardiol. 2018;253:183-8.

33. Mahmood M, Kendi AT, Farid S, Ajmal S, Johnson GB, Baddour LM, et al. Role of (18)F-FDG PET/ $\mathrm{CT}$ in the diagnosis of cardiovascular implantable electronic device infections: a meta-analysis. J Nucl Cardiol. 2019;26(3):958-70.

34. Juneau D, Golfam M, Hazra S, Zuckier LS, Garas S, Redpath C, et al. Positron emission tomography and single-photon emission computed tomography imaging in the diagnosis of cardiac implantable electronic device infection: a systematic review and meta-analysis. Circ Cardiovasc Imaging. 2017;10(4):e005772.

35. Treglia G, Maggi F, Bonomo L, Giordano A. Usefulness of fluorine-18 fluorodeoxyglucose PET/ computed tomography in diagnosis of aortitis and treatment response evaluation in a patient with aortic prosthesis. J Cardiovasc Med. 2011;12(11):814-6.

36. Reinders Folmer EI, Von Meijenfeldt GCI, Van der Laan MJ, Glaudemans AWJM, Slart RHJA, Saleem $\mathrm{BR}$, et al. Diagnostic imaging in vascular graft infection: a systematic review and meta-analysis. Eur J Vasc Endovasc Surg. 2018;56(5):719-29.

37. Rojoa D, Kontopodis N, Antoniou SA, Ioannou CV, Antoniou GA. 18F-FDG PET in the diagnosis of vascular prosthetic graft infection: a diagnostic test accuracy meta-analysis. Eur J Vasc Endovasc Surg. 2019;57(2):292-301.

38. Larici AR, Glaudemans AW, Del Ciello A, Slart RH, Calandriello L, Gheysens O. Radiological and nuclear medicine imaging of sarcoidosis. Q J Nucl Med Mol Imaging. 2018;62(1):14-33.

39. Treglia G, Annunziata S, Sobic-Saranovic D, Bertagna F, Caldarella C, Giovanella L. The role of 18F-FDG-PET and PET/CT in patients with sarcoidosis: an updated evidence-based review. Acad Radiol. 2014;21(5):675-84.

40. Treglia G, Taralli S, Giordano A. Emerging role of whole-body 18F-fluorodeoxyglucose positron emission tomography as a marker of disease activity in patients with sarcoidosis: a systematic review. Sarcoidosis Vasc Diffuse Lung Dis. 2011;28(2):87-94.

41. Slart RHJA, Glaudemans AWJM, Lancellotti P, Hyafil F, Blankstein R, Schwartz RG, et al. A joint procedural position statement on imaging in cardiac sarcoidosis: from the Cardiovascular and Inflammation \& Infection Committees of the European Association of Nuclear Medicine, the European Association of Cardiovascular Imaging, and the American Society of Nuclear Cardiology. J Nucl Cardiol. 2018;25(1):298-319.

42. Youssef G, Leung E, Mylonas I, Nery P, Williams K, Wisenberg G, et al. The use of 18F-FDG PET in the diagnosis of cardiac sarcoidosis: a systematic review and metaanalysis including the Ontario experience. J Nucl Med. 2012;53(2):241-8.

43. Tang R, Wang JT, Wang L, Le K, Huang Y, Hickey AJ, et al. Impact of patient preparation on the diagnostic performance of 18F-FDG PET in cardiac sarcoidosis: a systematic review and meta-analysis. Clin Nucl Med. 2016;41(7):e327-39.

44. Kim SJ, Pak K, Kim K. Diagnostic performance of F-18 FDG PET for detection of cardiac sarcoidosis; a systematic review and meta-analysis. J Nucl Cardiol. 2019. https://doi.org/10.1007/ s12350-018-01582-y.

45. Glaudemans AW, Prandini N, Di Girolamo M, Argento G, Lauri C, Lazzeri E, et al. Hybrid imaging of musculoskeletal infections. Q J Nucl Med Mol Imaging. 2018;62(1):3-13.

46. Wang GL, Zhao K, Liu ZF, Dong MJ, Yang SY. A meta-analysis of fluorodeoxyglucose-positron emission tomography versus scintigraphy in the evaluation of suspected osteomyelitis. Nucl Med Commun. 2011;32(12):1134-42. 
47. Treglia G, Sadeghi R, Annunziata S, Zakavi SR, Caldarella C, Muoio B, et al. Diagnostic performance of fluorine-18-fluorodeoxyglucose positron emission tomography for the diagnosis of osteomyelitis related to diabetic foot: a systematic review and a metaanalysis. Foot. 2013;23(4):140-8.

48. Lauri C, Tamminga M, Glaudemans AWJM, Juárez Orozco LE, Erba PA, Jutte PC, et al. Detection of osteomyelitis in the diabetic foot by imaging techniques: a systematic review and meta-analysis comparing MRI, white blood cell scintigraphy, and FDG-PET. Diabetes Care. 2017;40(8):1111-20.

49. Jin H, Yuan L, Li C, Kan Y, Hao R, Yang J. Diagnostic performance of FDG PET or PET/CT in prosthetic infection after arthroplasty: a meta-analysis. Q J Nucl Med Mol Imaging. 2014;58(1):85-93.

50. Verberne SJ, Raijmakers PG, Temmerman OP. The accuracy of imaging techniques in the assessment of periprosthetic hip infection: a systematic review and meta-analysis. J Bone Joint Surg Am. 2016;98(19):1638-45.

51. Verberne SJ, Sonnega RJ, Temmerman OP, Raijmakers PG. What is the accuracy of nuclear imaging in the assessment of periprosthetic knee infection? A meta-analysis. Clin Orthop Relat Res. 2017;475(5):1395-410.

52. Prodromou ML, Ziakas PD, Poulou LS, Karsaliakos P, Thanos L, Mylonakis E. FDG PET is a robust tool for the diagnosis of spondylodiscitis: a meta-analysis of diagnostic data. Clin Nucl Med. 2014;39(4):330-5.

53. Yin Y, Liu X, Yang X, Guo J, Wang Q, Chen L. Diagnostic value of FDG-PET versus magnetic resonance imaging for detecting spondylitis: a systematic review and meta-analysis. Spine J. 2018;18(12):2323-32.
54. Kim SJ, Pak K, Kim K, Lee JS. Comparing the diagnostic accuracies of F-18 fluorodeoxyglucose positron emission tomography and magnetic resonance imaging for the detection of spondylodiscitis: a metaanalysis. Spine. 2019;44(7):E414-22.

55. Treglia G, Focacci C, Caldarella C, Mattoli MV, Salsano M, Taralli S, et al. The role of nuclear medicine in the diagnosis of spondylodiscitis. Eur Rev Med Pharmacol Sci. 2012;16(Suppl 2):20-5.

56. Jamar F, Versari A, Galli F, Lecouvet F, Signore A. Molecular imaging of inflammatory arthritis and related disorders. Semin Nucl Med. 2018;48(3):277-90.

57. Descamps L, Olagne L, Merlin C, Cachin F, Soubrier M, Mathieu S. Utility of PET/CT in the diagnosis of inflammatory rheumatic diseases: a systematic review and meta-analysis. Ann Rheum Dis. 2018;77(11):e81.

58. Catalano O, Maccioni F, Lauri C, Auletta S, Dierckx R, Signore A. Hybrid imaging in Crohn's disease: from SPECT/CT to PET/MR and new image interpretation criteria. Q J Nucl Med Mol Imaging. 2018;62(1):40-55.

59. Treglia G, Quartuccio N, Sadeghi R, Farchione A, Caldarella C, Bertagna F, et al. Diagnostic performance of fluorine-18-fluorodeoxyglucose positron emission tomography in patients with chronic inflammatory bowel disease: a systematic review and a meta-analysis. J Crohns Colitis. 2013;7(5):345-54.

60. Zhang J, Li LF, Zhu YJ, Qiu H, Xu Q, Yang J, et al. Diagnostic performance of 18F-FDG-PET versus scintigraphy in patients with inflammatory bowel disease: a meta-analysis of prospective literature. Nucl Med Commun. 2014;35(12):1233-46.

Open Access This chapter is licensed under the terms of the Creative Commons Attribution 4.0 International License (http://creativecommons.org/licenses/by/4.0/), which permits use, sharing, adaptation, distribution and reproduction in any medium or format, as long as you give appropriate credit to the original author(s) and the source, provide a link to the Creative Commons license and indicate if changes were made.

The images or other third party material in this chapter are included in the chapter's Creative Commons license, unless indicated otherwise in a credit line to the material. If material is not included in the chapter's Creative Commons license and your intended use is not permitted by statutory regulation or exceeds the permitted use, you will need to obtain permission directly from the copyright holder.

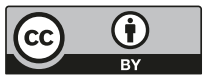

